\title{
Studi Korelasi Pengembangan Destinasi Wisata Alam Kebun Raya Samarinda Dengan Konservasi Lingkungan
}

\author{
Oleh \\ ${ }^{1}$ Rini Koen Iswandari ${ }^{2}$ Rinto Dwiatmojo ${ }^{3}$ Eman Sukmana ${ }^{4}$. Sabalius Uhai \\ ${ }^{1}$.rinikoeniswandari@polnes.ac.id ${ }^{2}$.rinto_dwiatmojoi@polnes.ac.id ${ }^{3} . e m a n s u k m a n a @ p o l n e s . a c . i d{ }^{4}$.sabaliusuhai@polnesa.ac.id \\ 1,2,3,4 Jurusan Pariwisata Politeknik Negeri Samarinda, Alamat, Kota Samarinda 75131, Indonesia \\ Jl. DR. Ciptomangunkusumo, Kampus Gunung Lipan, Samarinda, Kalimantan Timur, Indonesia 75131 \\ | Hot line: PABX (+62541) 260588, FAX: (+62541) 260355
}

Article history:

Received 2 Feb 2019

Revised 1 April 2019

Accepted 5 Juni 2019

\section{Mengajukan ISSN}

Keywords: Nature Tourism Destination Development, Environmental Conservation
Research Objectives to find out how the relationship between the development of tourist destinations and environmental conservation in Samarinda Botanical Gardens, the results of the study show that there is a very positive relationship and strong relationship between developments in terms of infrastructure, infrastructure carried out with environmental conservation for the progress tourism and for the preservation of the environment around the Samarinda Botanical Gardens Nature Tourism destination, which shows a positive and strong number between the independent variables (X), namely development with the dependent variable (Y) environmental conservation. Then the relationship between development and environmental conservation is smaller which shows there is significance

Copyright @ 2019 Politeknik Negeri Samarinda. All rights reserved. 


\section{Latar Belakang}

Pengembangan

merupakan

kebutuhan mendasar untuk memajukan sesuatu, tidak adanya suatu pengembangan maka tidak akan tercapai pula kemajuan. Sama halnya pemerintah Kota Samarinda yang sedang menggerakkan pengembangan-pengembangan untuk memajukan pariwisata yang dimilikinya. Pengembangan yang dilakukan salah satunya di destinasi wisata alam Kebun Raya Samarinda di daerah Samarinda. Destinasi wisata ini juga sedang melakukan suatu pengembangan dengan melakukan pembangunan-pembangunan dan pengembangan-pengembangan

terhadap destinasi wisata alam Kebun Raya Samarinda seperti pengembangan dan pembangunan yang mencakup segi infrastruktur dan sarana prasarana seperti lokasi atraksi utama, jalan, dan pembangunan pendukung atraksi utama, karena tempat wisata ini tergolong cukup popular, maka pemerintah kota Samarinda dan instansi-instansi terkait mencanangkan suatu pengembangan terhadap destinasi wisata alam Kebun Raya Samarinda ini lebih intensif lagi. Dari pengembangan yang dilakukan dalam mengembangkan destinasi wisata Kebun Raya Samarinda ini seperti pengembangan infrastruktur, sarana dan prasarana.

\section{Pengembangan-}

pengembangan yang dilakukan tersebut semata untuk meningkatkan dan memanfaatkan potensi yang dimiliki destinasi wisata alam Kebun Raya Samarinda ini, akan tetapi pengembangan tersebut harus merujuk pada permasalahan mendasar tentang dampak dari adanya pengembanganpengembangan yang tidak memperhatikan keberlangsungan lingkungan alam di masa mendatang, padahal keasrian lingkungan merupakan kunci keberlangsungan siklus hidup makhluk hidup yang ada di bumi ini dan di masa mendatang. Seperti pernyataan adanya pembangunan dan juga pengembangan suatu kawasan, maka kata kemajuan itu akan jauh dari yang diharapkan, akan tetapi pembangunan dan pengembangan yang memperhatikan kaidah-kaidah dasar pengembangan dan pembangunan berkelanjutan akan mematahkan stigma buruk tentang pengembangan yang identik dengan dampak negatif terhadap lingkungan.

Dari latar belakang masalah diatas maka akan ditemukan permasalahan dalam proses pengembangan destinasi wisata alam kebun Raya Samarinda ini. Apakah pengembangan yang mencakup insfrastruktur seperti pelebaran jalan, dan bangunan-bangunan pendukung atraksi utama ini akan menimbulkan dampak negatif ataupun dampak positif terhadap hubungannya dengan konservasi lingkungan alam sekitar .

\section{Kajian Pustaka}

Seorang wisatawan mengadakan perjalanan wisata karena didorong oleh berbagai motif yang tercermin dalam berbagai macam jenis pariwisata. Bagi daerah sangat perlu mempelajari motif ini karena berhubungan dengan fasilitas yang 
perlu disiapkan dan program promosinya. Spillane (1987:29) membedakan jenis pariwisata, yaitu: Pariwisata untuk menikmati perjalanan (pleasure tourism), Pariwisata untuk rekreasi (recreationtourism), Pariwisata untuk kebudayaan (cultural tourism), Pariwisata untuk olahraga (sport tourisnm), Pariwisata untuk usaha dagang (business tourism), Pariwisata untuk berkonvensi (conventiontourism).

\begin{tabular}{lrr}
\multicolumn{2}{c}{ Sedangan menurut } & Yoeti \\
$(1997: 5)$ & dalam bukunya & yang \\
berjudul & "Perencanan & dan
\end{tabular} berjudul "Perencanan dan berpendapat bahwa pengembangan adalah usaha yang dilakukan secara sadar dan berencana untuk memperbaiki produk yang sedang berjalan atau menambah jenis produk yang dihasilkan ataupun yang akan dipasarkan dan Menurut Sunu (2001:2) menambahkan definisi lingkungan adalah sekeliling tempat organisasi beroperasi, termasuk udara, air, tanah, sumber daya alam, flora, fauna, manusia dan hubungan diantaranya.

\section{Metode Penelitian}

\section{Lokasi Penelitian}

Penelitian ini berlokasi di destinasi wisata alam kebun raya Samarinda.Alasan melakukan penelitian di tempat tersebut karena destinasi wisata alam kebun raya samarinda merupakan destinasi wisata yang berbasis wisata alam yang tergolong populer di Samarinda yang belum semuanya mengalami pembangunanpembangunan secara penuh.

\section{Populasi dan Sampel}

- Teknik Pengambilan Sampel

Metode penarikan sampel/pengambilan sampel yang digunakan dalam penelitian ini adalah random sampling dimana peneliti memberikan kesempatan yang sama pada anggota sampel (probability sampling)

- Ukuran Sampel

Cuplikan sampel (unit analisis) setidaknya diambil berdasarkan ukuran sampel minimal dari jumlah anggota populasi yang sangat besar.

3. Teknik Pengumpulan Data

Observasi , Wawancara Kuesioner Dokumentasi

4. Variabel dan Indikator Penelitian

a. Variabel Independent (bebas)

Adalah variabel yang nilai-nilainya tidak tergantung pada variabel lainnya, biasanya disimbolkan dengan X. Dalam penelitian ini variabel independent (bebas) adalah Pengembangan dengan indikator antara lain :

\section{Infrastruktur}

- Pengairan terhadap ragam keperluan di lokasi utama.

- bangunan-bangunan gedung di lokasi utama.

\section{Sarana Prasarana}

- Pembangunan tempat penjualan makanan dan minuman. 
- Perhubungan

(Renovasi jalan
menuju destinasi
wisata).

b. Variabel

Dependent (terikat)

Variabel yang nilainilainya terikat pada variabel lainnya, biasanya disimbolkan dengan Y. Variabel itu merupakan variabel yang diramalkan atau diterangkan nilainya, dan dalam penelitian ini variabel dependent (variabel terikat) adalah Konservasi Lingkungan.

\section{Definisi Konseptual}

a. Infrastruktur

Merupakan pendukung utama fungsifungsi sistem sosial dan ekonomi dalam kehidupan sehari-hari masyarakat serta dapat didefinisikan sebagai fasilitas-fasilitas atau unsur-unsur dasar serta aset fisik yang dibangun dan yang dibutuhkan untuk berfungsinya sistem sosial dan sistem ekonomi masyarakat. Di dalam penelitian ini terdapat 2 (dua) indikator: Bangunan-bangunan gedung di lokasi utama destinasi wisata serta penyediaan air lokasi utama destinasi wisata.

b. Sarana dan Prasarana

Prasarana

kepariwisataan adalah semua fasilitas yang memungkinkan agar sarana kepariwisataan dapat hidup dan berkembang sehingga dapat memberikan pelayanan untuk memuaskan kebutuhan wisatawan yang beraneka ragam. Terdapat 2 indikator dari penilitian ini yaitu: Perhubungan (renovasi jalan) serta bangunan rumah makan dan bangunan penjualan cinderamata.

\section{Definisi Operasional}

Berdasarkan pada variable dan konsep-konsep di atas, maka definisi operasional dalam penelitian ini digunakan untuk mengukur setiap variable-variabel yang diteliti, yaitu variable $\mathrm{X}$ dan Variabel Y.

a. Indikator Infrastruktur

1) Pembangunan bangunan-bangunan

di lokasi utama destinasi wisata diukur dengan pemilihan letak lokasi bagunan.

2) Penyediaan air di lokasi Utama destinasi wisata diukur dengan pembuatan saluran air.

b. Indikator Pengembangan Sarana dan Prasarana

1) Pembangunan tempat penjualan makanan diukur dengan pemilihan letak tempat penjualan tersebut.

2) Perhubungan (renovasi jalan) diukur 
dengan seberapa besar dampak perluasan jalan.

c. Indikator Konservasi

1) Kelestarian alam diukur dengan pemeliharaan berkelanjutan.

2) Keanekaragaman biologis diukur dengan perlindungan terhadap kelestarian hidup

keanekaragaman biologis yang ada di sekitar lingkungan destinasi wisata.

\section{Teknik Analisis Data}

Dalam penelitian ini penulis menggunakan analisis korelasi product moment, menurut Arikunto (2006:271), korelasi product moment digunakan untuk menentukan hubungan antara dua gejala interval seperti nilai matematika dan IPA.

\section{hipotesis:}

\section{Langkah-langkah}

a. Menentukan hipotesis

Ho : $\mathrm{b}=0$, artinya masing-masing variabel bebas tidak mempunyai hubungan yang signifikan terhadap variabel terikat.

$\mathrm{Ha}: b \neq 0$, artinya masing-masing variabel bebas mempunyai hubunganyang signifikan terhadap variabel terikat.

b. Menentukan besarnya angka $\mathrm{t}$ hitung dengan menggunakan program SPSS 18.0.

c. Menghitung besarnya angka $t$ tabel dengan ketentuan taraf signifikan sebesar 0,05 dan derajat kebebasan $(\mathrm{dk})=\mathrm{n}-2$.

d. Menentukan kesimpulan tentang uji hipotesisnya sebagai berikut:

Jika $\mathrm{t}$ hitung $>\mathrm{t}$ tabel maka Ho ditolak dan Ha diterima.

Jika t hitung < $\mathrm{t}$ tabel maka Ho diterima dan Ha ditolak.

\section{Skala Likert}

Dalam penelitian ini skala Likert digunakan untuk pengukuran Pengembangan Insfrastruktur dan Sarana Prasarana:

a. Sangat setuju, diberi skor

$$
4
$$

b. setuju, diberi skor

c. kurang setuju, diberi skor

d. sangat tidak setuju, diberi skor

\section{1}

\section{Hasil dan Pembahasan}

Teknik analisis data yang digunakan dalam penelitian ini adalah Corelasi Product Moment yaitu keterkaitan yang melibatkan 2 (dua) variable. Analisis ini digunakan untuk mengetahui hubungan dari suatu variabel dependen terhadap variable independen. Perhitungan data dalam penelitian ini menggunakan program SPSS 18.0 yang membantu dalam 
pengujian model yang telah ditentukan, mencari nilai korelasi dari tiap-tiap variabel serta pengujian hipotesis secara parsial maupun bersama-bersama.

Berdasarkan output Dari hasil perhitungan menggunankan SPSS 18.0 diatas diketahui nilai signifikan dari output antara Pengembangan Destinasi Wisata (X) yang meliputi infrastruktur, sarana dan prasarana dengan Konservasi Lingkungan (Y) dari tabel hasil perhitungan ditemukan bahwa significance (2-tailed) atau hasil signifikasi adalah " 0,000 " yang apabila dibandingkan dengan level of significance $\alpha=$ 0,05 adalah lebih kecil dari taraf signifikan yang menunjukkan terdapat hubungan yang signifikan antara pengembangan dengan konservasi lingkungan.

Berdasarkan nilai dari output diatas diketahui bahwa nilai pearson correlation yang dihubungkan antara masingmasing variabel yang bernilai $0,604^{* *}$ adalah bernilai positif sehingga terdapat keterkaitan antara kedua variabel independen dan dependen, ini berarti terdapat korelasi yang positif dan kuat antara variabel independent (X) yaitu pengembangan yang meliputi infrastruktur, sarana dan prasarana dengan variabel dependent (Y) yaitu konservasi lingkungan.

Menentukan Hipotesis Nihil (Ho) dan Hipotesis Alternatif (Ha)
1) $\mathrm{Ho}=\beta_{1}=0, \quad$ variabel Pengembangan Destinasi Wisata yang meliputi infrastruktur, sarana dan prasarana tidak ada hubungan secara signifikan terhadap Konservasi Lingkungan di Wisata Kebun Raya Samarinda Kota Samarinda.

\section{Kesimpulan Ho:}

Hasil perhitungan diketahui level of significance $\alpha=0,05$ dan diperoleh signifikasi sebesar 0.000 dan dibandingkan dengan level signifikan 0,05 dari hasil 0,000 < 0,05 maka Ho ditolak karena variabel Pengembangan Destinasi Wisata terdapat hubungan secara signifikan dengan Konservasi Lingkungan Wisata Alam Kebun Raya Samarinda di Kota Samarinda.

2) $\mathrm{Ha}=\beta_{1} \neq 0, \quad$ variabel

Pengembangan Destinasi Wisata ada hubungan secara signifikan dengan Konservasi Lingkungan di Wisata Alam Kebun Raya Samarinda

\section{Kesimpulan Ha:}

Hasil perhitungan diketahui level of significance $\alpha=0,05$ dan diperoleh signifikasi sebesar 0.000 dan dibandingkan dengan level signifikan 0,05 dari hasil $0,000<$ 0,05 maka Ha diterima dan variabel Pengembangan Destinasi Wisata memiliki hubungan secara signifikan terhadap Konservasi Lingkungan Wisata Alam Kebun Raya Samarinda

Dari pernyataan-pernyataan
asil output perhitungan
menggunakan product moment
an hasil dari kesimpulan


hipotesis diatas menghasilkan hasil yang menunjukkan adanya hubungan positif antara pengembangan-pengembangan yang dilakukan di destinasi wisata alam Kebun Raya Samarinda, seperti dalam hal infrastruktur, sarana dan prasarana dengan konservasi lingkungan. Hal tersebut memang demikian, pada dasarnya wisata alam adalah wisata yang berbasis alam yang sangat berhubungan erat dengan lingkungan.Pengembangan yang dilakukan disemua wisata alam haruslah sinkron dengan lingkungan alamiah karena atraksi wisata utama dari wisata jenis ini adalah keasrian khas alam yang dimiliki suatu daerah.

Tanpa adanya keterikatan dengan alam berarti suatu destinasi wisata tidak bisa dikatakan sebagai destinasi wisata alam, itu mengartikan apabila alam rusak, maka rusak pula atraksi wisata alam tersebut. Banyak sekali kejadian yang salah untuk proses pengembangan untuk memajukan destinasi wisata alam di daerah-daerah lain. Mereka hanya sebatas membangun, memperindah sisi eksternalnya suatu destinasi wisata alam saja untuk kebutuhan wisatawan tanpa mempedulikan sisi internal yang sangat penting untuk kebutuhan suatu destinasi wisata alam kedepannya yaitu lingkungan alam.

Dalam pengembangan tersebut mereka hanya bercermin dari peradaban modern yang semua aspek berbau modern tanpa memperhatikan dasar alamiah. Dengan membangun bermacam gedung industri tanpa pola keamanan, kenyamanan dan kesejahteraan terhadap manusia secara tidak langsung hal tersebut akan terlihat condong ke perilaku ekonomi kapitalis tanpa memperdulikan lingkungan sekitar. Pengembangan seperti ini dengan tidak sadar membawa kearah kemunduran disegala aspek, hanya memperoleh kemajuan instant diawalnya setelah tindakan dari suatu perencanaan pengembangan yang dilakukan, khususnya dalam penelitian ini adalah pengembangan terhadap destinasi wisata alam.

Dimasa jangka panjang bukan kemajuan yang diperoleh melainkan semakin mengalami kemerosotan dan rencana untuk memajukan wisata alam adalah hal yang sangat jauh dari yang diharapkan karena lignkungan alamiah yang merupakan elemen penting dari destinasi wisata telah rusak.

Pengembangan memanglah sangat dibutuhkan dalam hal kemajuan untuk segala aspek yang diusahakan. Pembangunan tidak semata hanya membangun dan mengembangkan. Bahwasannya pengembangan yang dibutuhkan dalam pengembangan destinasi wisata alam adalah pengembangan yang tetap mempedulikan habitat 
keasrian lingkungan destinasi wisata alam ke depannya ataupun pengembangan berkelanjutan yang erat kaitannya dengan konservasi lingkungan. Dengan itu kemajuan akan diperoleh dalam hal ini adalah kemajuan destinasi wisata alam Kebun Raya Samarinda tanpa mengorbankan habitat keasrian lingkungan alam sekitar destinasi wisata tersebut. Tanpa pengembangan berwawasan lingkungan maka akan terjadi kerusakan lingkungan yang akan menjadi semakin parah dengan waktu. Menjaga kemampuan lingkungan untuk mendukung pengembangan merupakan usaha untuk mencapai pembangunan jangka panjang yang mencakup jangka waktu antar generasi, yaitu pengembangan dengan tetap mengedepankan kelestarian lingkungan alamiah atau konservasi lingkungan ataupun sering kita dengar pembangunan berkelanjutan.

Dengan mencakup jangka waktu antar generasi, dalam proses pengembangan tidaklah untuk kita saja, melainkan untuk anak cucu di generasi mendatang. Untuk mencapai itu semua pengembangan haruslah berwawasan lingkungan dengan menggunakan sumberdaya secara bijaksana agar berdaya guna lebih bagi manusia dan habitat alamiah lingkungan untuk masa sekarang dan masa yang akan datang. "Dan kami hamparkan bumi itu dan
Kami letakkan padamu gununggunung yang kokoh dan Kami tumbuhkan padanya segala macam tanaman yang indah dipandang mata” (QS 50:7). Kekayaan di bumi ini sudah semuanya tersedia untuk manusia dan memberikan kesejahteraan termasuk alam yang dikelola oleh manusia dalam hal ini adalah destinasi wisata alam dengan mengandalkan atraksi wisata berupa kekayaan alam, akan tetapi pengelolaan tersebut haruslah selaras dengan kelestarian habitat alamiah alam dan perilaku semacam itu secara tidak langsung adalah suatu bentuk ucapan terimakasih kepada Tuhan yang telah melimpahkan itu semua untuk kita kelola dan kita konsumsi. "Hai sekalian manusia, makanlah yang halal lagi baik dari apa yang terdapat dibumi..." (QS 2:168). "Dan janganlah kamu membuat kerusakan di muka bumi sesudah (Allah) memperbaikinya....."(QS 7:56).

Dari penelitian yang telah penulis lakukan, sudah tergambar jelas bahwasannya pembangunan dan pengembangan yang dilakukan di destinasi Wisata Alam Kebun Raya Samarinda yang berupa infrastruktur, sarana dan prasana sudah memperhatikan konservasi lingkungan alam sekitar destinasi wisata. Seperti halnya pembangunanpembangunan fasilitas utama seperti gazebo, musholla dan fasilitas yang ada di sekitar 


$\begin{array}{lr}\text { destinasi utama } & \text { juga } \\ \text { memperhatikan } & \text { keasrian } \\ \text { lingkungan dengan tidak } \\ \text { menebang pohon-pohon dan } \\ \text { menggusur habitat hewan khas } \\ \text { tempat ini. Dilihat dari sarana } \\ \text { prasarana yang mendukung } \\ \text { destinasi utama di sisi eksternal } \\ \text { seperti sarana dan prasarana, } \\ \text { sebagai contoh pelebaran jalan } \\ \text { yang dilakukan sebagai } \\ \text { kelancaran wisatawan untuk } \\ \text { menuju destinasi juga } \\ \text { memperhatikan } \\ \text { lingkungan, dimana dalam proses } \\ \text { pelebaran aksesbilitas jalan } \\ \text { tersebut tidak ada yang menjadi } \\ \text { korban dari pelebaran ini, } \\ \text { termasuk lahan milik penduduk } \\ \text { dan tanaman-tanaman asli tempat } \\ \text { ini. Untuk pengembangan } \\ \text { berkelanjutan juga terdapat } \\ \text { pengelolaan dengan menanam } \\ \text { bunga-bunga khas daerah } \\ \text { pegunungan dan pohon pinus di } \\ \text { sekitar destinasi wisata agar tetap } \\ \text { tercipta siklus baru untuk keasrian } \\ \text { lingkungan alaminya. Jadi, } \\ \text { pengembangan destinasi Wisata } \\ \text { alam Kebun Raya Samarinda } \\ \text { memang sangat memperhatikan } \\ \text { konservasi lingkungan dengan } \\ \text { tidak semata-mata membangun } \\ \text { tanpa memperhatikan keasrian } \\ \text { alam sekitar destinasi wisata ini, } \\ \text { dengan tetap mengedepankan } \\ \text { pembangunan dan pengembangan } \\ \text { berwawasan lingkungan di tengah } \\ \text { hiruk pikuk pembangunan yang } \\ \text { mengorbankan kelestarian } \\ \text { lingkungan alamnya. }\end{array}$

\section{Kesimpulan Dan Saran}

Terdapat hubungan yang sangat positif dan hubungan yang kuat antara pengembanganpengembangan dari segi infrastruktur, sarana dan prasarana yang dilakukan dengan konservasi lingkungan untuk kemajuan destinasi wisata dan untuk kelestarian lingkungan sekitar destinasi Wisata Alam Kebun Raya Samarinda, dilihat dari hasil penelitian yang menunjukkan angka positif dari perhitungan yang menggunakan alat bantu hitung SPSS 18.0, dimana pearson correlation menunjukkan angka ",604" yang bernilai positif, nilai tersebut menunjukkan adanya hubungan yang positif dan kuat antara variabel independent (X) yaitu pengembangan yang memiliki indikator infrastruktur, sarana dan prasarana dengan variabel dependent (Y) yaitu konservasi lingkungan. Kemudian dari tabel hasil perhitungan ditemukan bahwa sig. (2-tailed) atau hasil signifikasi adalah “,000" yang apabila dibandingkan dengan level of significance $\alpha=0,05$ adalah lebih kecil yang menunjukkan terdapat signifikasi hubungan antara pengembangan dengan konservasi lingkungan. Sehingga hipotesis Ho ditolak dan $\mathrm{Ha}$ diterima karena terdapat hubungan yang signifikan antara pengembangan destinasi wisata alam Kebun Raya Samarinda dengan konservasi lingkungan. Sehingga apabila pengembangan destinasi wisata alam Kebun Raya 
Samarinda

mengalami peningkatan maka diikuti pula oleh peningkatan konservasi lingkungan.

Perlu adanya kerjasama antara instansi yang tidak secara langsung terkait dengan pariwisata namun mempunyai hubungan erat dengan kelestarian lingkungan. Bahwasannya pengembangan Destinasi Wisata Alam Kebun Raya Samarinda tidak hanya melakukan pengembangan untuk mengembangkan wisatanya akan tetapi pengembangan tersebut berpedoman juga terhadap keberlanjutan keasrian lokal di masa mendatang dikarenakan jenis destinasi wisata ini adalah Wisata Alam yang sangat erat kaitannya dengan keasrian lokal untuk atraksi wisata utamanya. Maka dari itu gap antara instansiinstansi tersebut haruslah dibuang agar tercipta suatu kerjasama yang saling membangun alam yang berdaya guna bagi manusia dan bumi tanpa merusak keasrian alam tersebut dimasa mendatang, di penghuni generasi yang akan datang.

\section{DAFTAR PUSTAKA}

Darmawan, Deni. 2013. Metode Penelitian Kuantitatif. Bandung. PT Remaja Rosdakarta
Fandeli, Chafid. 1995. Dasar-Dasar Manajemen Kepariwisataan. Yogyakarta. Liberty.

Hasan, Ali. 2009. Marketing. Yogyakarta. Medpress

— , Ali. 2013. Marketing dan Kasus-kasus pilihan. Yogyakarta. CAPS

Kuncoro, Mudrajad. 2004. Metode Kuantitatif Teori dan Aplikasi Untuk Bisnis dan Ekonomi. Yogyakarta. AMP YKPN

Musanef. 1996. Manajemen Usaha Pariwisata. Jakarta. Gunung Agung.

Pendit, Nyoman S. 2002. Ilmu Pariwisata " sebuah pengantar perdana”. Jakarta. PT Pradnya Paramita

Pitana , I Gde dan Gayatri. 2005. Sosiologi Pariwisata. Yogyakarta. Andi.

, I Gde dan Diarta. 2009. Pengantar Ilmu Pariwisata. Yogyakarta. Andi.

Sihite, Richard. 2000. Tourism Industry ( Kepariwisataan). Surabaya. SIC

Siregar, Syofian. 2013. Metode Penelitian Kuantitatif dan SPSS. Jakarta. Kencana Prenada.

Sugiyono. 2013. Metode Penelitian Manajemen. Bandung. CV Alfabeta. 
— . 2013. Metode Penelitian Kuantitatif,Kualitatif, Dan $R \& D$. Bandung. $\quad \mathrm{CV}$ Alfabeta.

Sudjana. 1996. Metode Statistik. Bandung. Tarsito.

Sunyoto, Danang. 2011. Metode Penelitian Ekonomi. Yogyakarta. CAPS

Suwantoro, Gamal. 2004. Dasar Dasar Pariwisata. Yogyakarta. Andi

Tjiptono, Fandy. 1997. Strategi Pemasaran. Yogyakarta. Andi.

Wahab, Salah Pd.D. 1997. Pemasaran Pariwisata. Jakarta. PT Pradnya Paramita.

Yoeti, Oka A. 1996. Pengantar Ilmu Pariwisata. Bandung. Angkasa. 